\title{
Rancang Bangun Sistem Informasi Eksekutif Pada STAHN Gde Pudja Mataram
}

\author{
(Design and Implementation of Executive Information System at STAHN Gde Pudja \\ Mataram)
}

\author{
Syahroni Hidayat, Sri Endang Anjarwani, I Wayan Agus Arimbawa \\ Prodi. Teknik Informatika, Fakultas Teknik, Universitas Mataram \\ J1. Majapahit 62, Mataram, Lombok NTB, INDONESIA \\ Email: roni.ayat@gmail.com, endang@unram.ac.id,arimbawa@unram.ac.id
}

\begin{abstract}
The optimal use of information and communication technology can improve the development of a company and educational institution. One system that is currently developing is the executive information system (SIE). The Executive Information System is an information system aimed at facilitating information needs for executives. STAHN Gde Pudja Mataram is the only National Hindu Religion School in NTB Province with very rapid development that requires executive information systems to facilitate obtaining information to support accreditation of STAHN Gde Pudja's academic information system in Mataram. This Executive Information System is built with framework codeiter and uses the concept of a data warehouse by analyzing important data. The main concept of a data warehouse is that the database is stored for business analysis that can be accessed efficiently by separating the database from the operational system. The operational database is processed through the Extract, Transform, Load process which is a process that must be passed to produce a good and appropriate data warehouse. Maximum results can be obtained based on the order of the data warehouse architecture design, namely by selecting tables / data in the operational database SIA STAHN Gde Pudja Mataram according to the needs of the information to be displayed. Data that has been selected is then trimmed and loaded into the data warehouse. This executive information system is able to provide information about students, student achievement, student status and data about lecturers in Pudja Mataram Gde STAHN in the form of graphs and tables. The information provided is used to assist executives in taking important policies for the progress of the STAHN campus in Gde Pudja Mataram in the future.
\end{abstract}

Key words: Executive Information System, Data Warehouse, CodeIgniter, E-T-L, Waterfall System Development

\section{Pendahuluan}

Pemanfaatan teknologi informasi dan komunikasi secara optimal dapat membuat perkembangan suatu perusahaan/bisnis dan instansi pendidikan menjadi sangat pesat. Salah satu sistem yang berkembang saat ini adalah sistem informasi eksekutif (SIE). Definisi sistem Informasi Eksekutif adalah "sebagai salah satu tipe sistem informasi berbasis komputer yang ditujukan untuk memfasilitasi kebutuhan informasi yang berkaitan dengan tercapainya tujuan suatu organisasi bagi eksekutif[1]". Sistem informasi yang berbasis komputer yang dirancang dan dioperasikan secara langsung oleh eksekutif tanpa adanya perantara [2].

STAHN Gde Pudja Mataram merupakan satu-satunya Sekolah Tinggi Agama Hindu Negeri di Provinsi NTB dengan perkembangan yang sangat pesat. Proses akreditasi membutuhkan berbagai informasi, salah satunya adalah informasi akademik. Sistem informasi akademik (SIA) STAHN Gde Pudja Mataram saat ini belum dapat mengolah informasi sampai pada level eksekutif untuk menunjang hal tersebut. Oleh karena itu diperlukan sebuah sistem informasi yang dapat menunjang pengolahan informasi akademik sampai pada level eksekutif. Selain untuk proses akreditasi, sistem informasi eksekutif juga digunakan untuk menyajikan informasi yang dibutuhkan untuk mengambil keputusan pengelolaan kampus.

\section{KAJIAN PUSTAKA}

Penelitian sebelumnya yang berkaitan dengan "Executive Information System telah dibuat untuk studi kasus di pada sekolah menengah atas [1]. Sistem informasi eksekutif pada penelitian ini menggunakan konsep data warehouse dengan fitur analisis tren nilai dan analisis ketercapaian program kerja sekolah. Sistem informasi eksekutif ini kemudian diukur tingkat keefektifannya di dalam organisasi sekolah. Penelitian lain [3] membahas perancangan dan pengembangan sistem informasi eksekutif pada perguruan tinggi, berbasis web, dan dengan pendekatan data warehouse. Penelitian lain yang terkait pemanfaatan sistem informasi eksekutif di perguruan tinggi [3], [4], [5] menghasilkan sebuah sistem informasi yang dapat membantu eksekutif perguruan tinggi dalam mengambil keputusan.

Penelitian lainnya yang berkaitan dengan "Analisis dan perancangan sistem informasi eksekutif studi kasus pada sekretariat kabinet'[6]. Sistem informasi ini dibangun untuk melakukan analisis dan menyediakan informasi yang diperlukan oleh presiden dan wakil presiden secara mudah dan cepat serta dapat dipertanggung-jawabkan. Informasi yang dihasilkan adalah berupa ringkasan (summary) hasil analisis terhadap evaluasi dan peninjauan pelaksanaan kebijakan dan program pemerintah. Data warehouse 
merupakan pengintegrasian database aplikasi SIDKAB, SIPUU, SIMPEG serta rancangan sistem informasi eksekutif.

Penelitian mengenai pengembangan sistem informasi dengan framework CodeIgniter telah banyak dikembangkan seperti pada [7], [8], sehingga dapat dijadikan dasar pengembangan sistem pada penelitian ini.

\section{Metode Penelitian}

\section{A. Metode Penelitian}

Tahapan penelitian ini dapat dilihat pada diagram alir penelitian seperti Gambar 1.

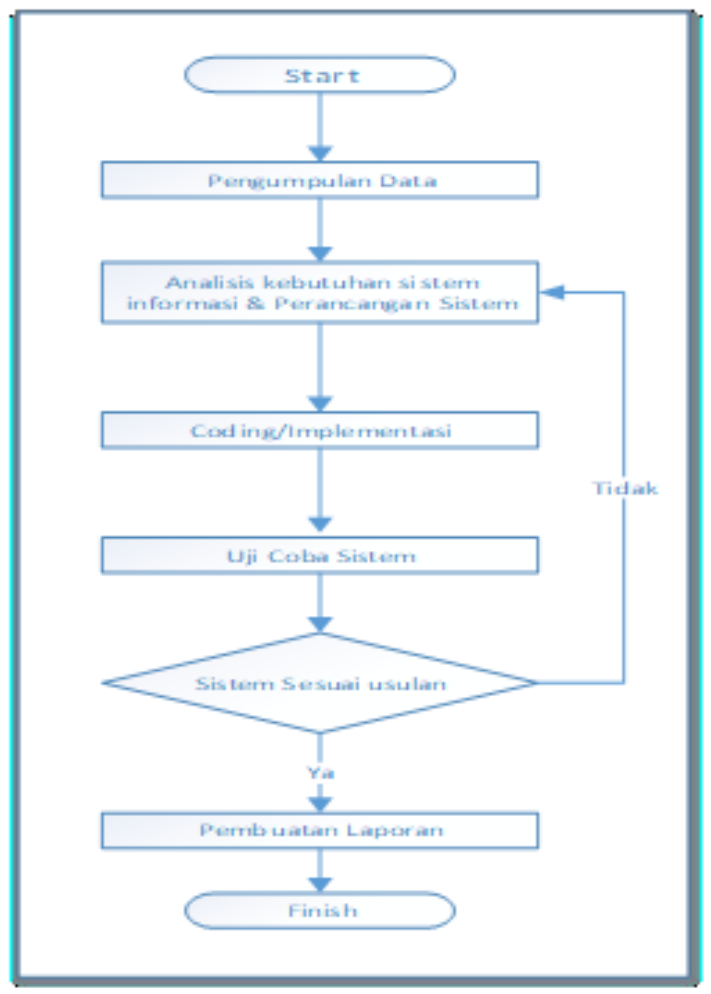

Gambar 1. Diagram alir penelitian.

\section{B. Analisa Data Warehouse}

Merupakan suatu tahap pemetaan analisa yang akan dilaksanakan pada data warehouse. Berdasarkan penyusunan kebutuhan yang telah dilakukan maka analisa data yang menjadi kebutuhan sistem adalah sebagai berikut : tabel fakta (fact table) merupakan suau tabel yang berisi sesuatu yang dapat diukur (measureable), seperti harga, jumlah barang, dan sebagainya. Fact table juga merupakan kumpulan foreign key dari primary key yang terdapat pada masing-masing dimension table. Fact table juga mengandung data yang historis yaitu data masa lampau. Dimension table (tabel dimensi) adalah tabel yang berisi data detail yang menjelaskan foreign key yang terdapat pada fact table. Atribut-atribut yang terdapat pada dimension table dibuat secara berjenjang untuk memudahkan proses query. Analisa data warehouse digunakan untuk membantu mempermudah memetakan kebutuhan dari eksekutif STAHN Gde Pudja Mataram, kemudian dari tabel mana saja kebutuhan yang telah dijabarkan pada user stories akan ditampilkan kepada eksekutif STAHN Gde Pudja Mataram.

\section{Perancangan Data Warehouse}

Rancangan pembuatan data warehouse dapat dilihat pada diagram alir sistem informasi eksekutif seperti Gambar 2.

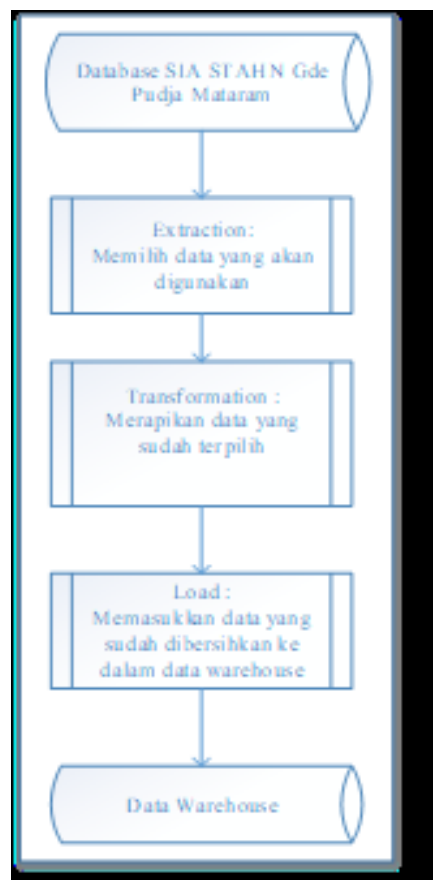

Gambar 2. Rancangan arsitektur data warehouse sistem informasi eksekutif STAHN Gde Pudja Mataram.

Rancangan arsitektur data warehouse sistem informasi eksekutif STAHN Gde Pudja Mataram dimulai dengan database Sistem Informasi Akademik STAHN Gde Pudja Mataram. Setelah data source didapatkan langkah selanjutnya yang akan di lakukan adalah mengekstraksi database tersebut sesuai dengan data warehouse yang akan dibangun. Data yang sudah diekstraksi, kemudian yang dilakukan adalah mentransformasi data tersebut. Proses transformasi dilakukan dengan merapikan data, memperbaiki nama field, kemudian atribut. Selanjutnya adalah data di-load ke dalam gudang data yang sudah dibangun dengan SQL sehingga terbentuklah data warehouse yang siap digunakan untuk memberikan informasi.

\section{Pemodelan Data Dimensional}

Skema yang digunakan dalam memodelkan data dimensional adalah star scheme. Keunggulan star scheme adalah menciptakan rancangan database yang menyediakan response time yang cepat, menyediakan rancangan yang dapat dimodifikasi atau ditambah secara 
berulang-ulang dengan mudah sesuai dengan perkembangan data warehouse. Tabel fakta yang terbentuk dari user stories data warehouse merupakan tabel yang berhubungan dengan analisis kebutuhan dari sistem informasi eksekutif STAHN Gde Pudja Mataram.

Perancangan star scheme data warehouse STAHN Gde Pudja Mataram dibagi ke dalam dua bagian yaitu untuk data KRS dan data status mahasiswa. Masing-masing skema memiliki sebuah tabel fakta yaitu krs dan satus_mahasiswa. Kedua skema tersebut dapat dilihat dalam Gambar 3 dan Gambar 4.

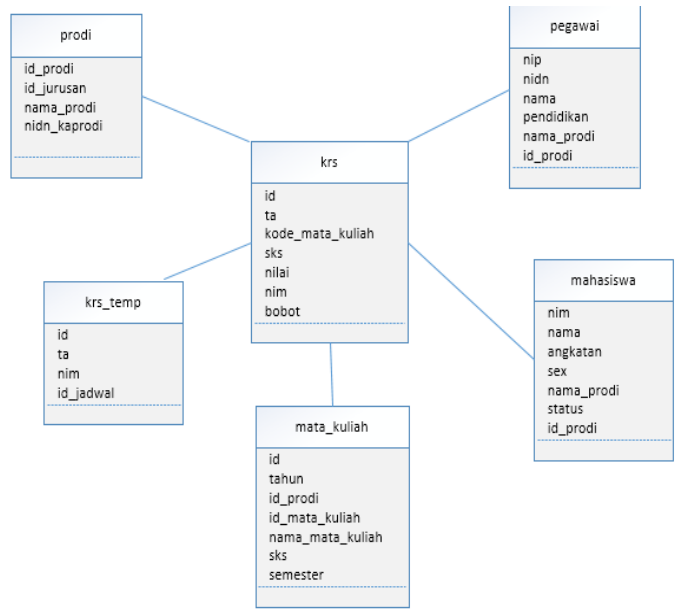

Gambar 3. Star scheme KRS.

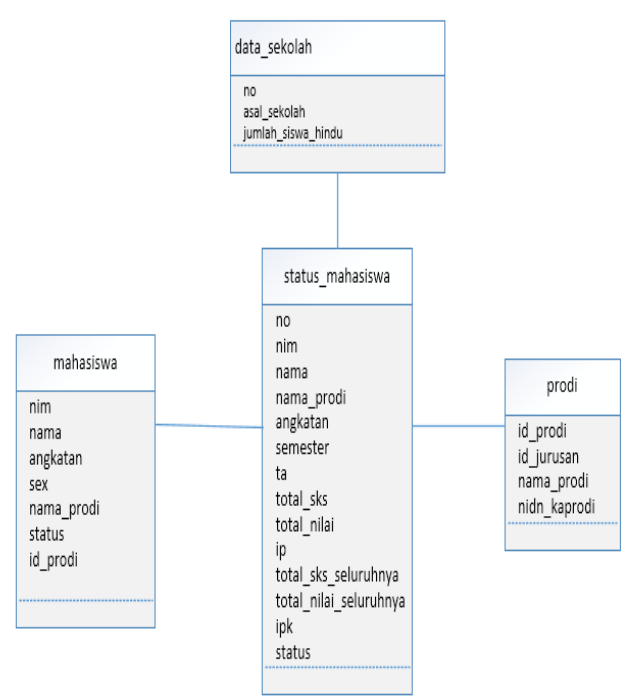

Gambar 4. Star scheme status mahasiswa.

\section{E. Perancangan Diagram Sistem}

Berikut ini merupakan rancangan diagram sistem informasi eksekutif STAHN Gde Pudja Mataram.

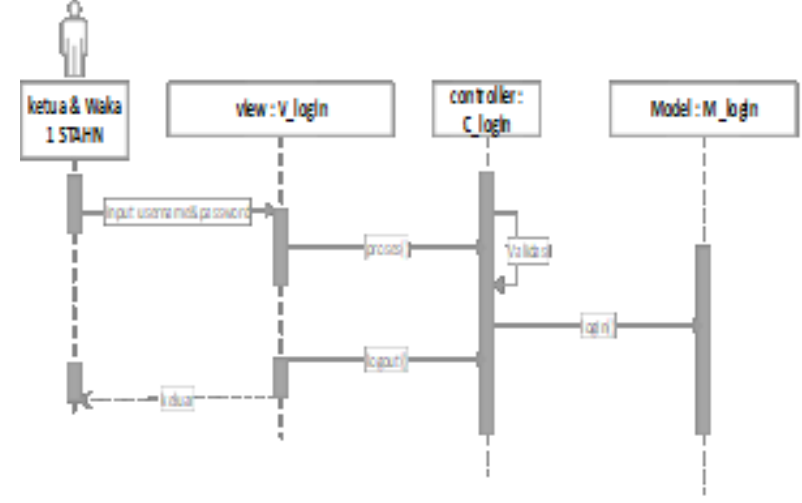

Gambar 5. Sequence diagram login ketua \& waka 1

Gambar 5 menunjukkan diagram sequence untuk proses login ketua dan Waka 1. Proses login melibatkan kelas C_login dan M_login pada Codeigniter.

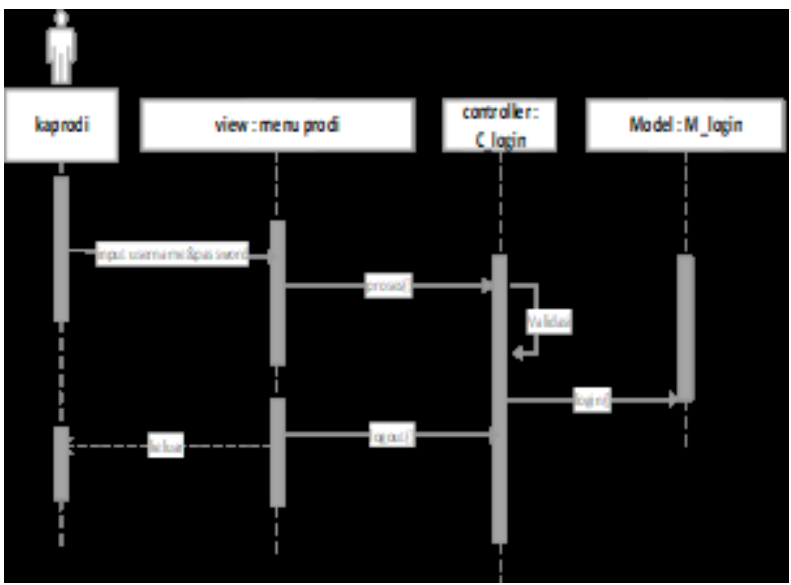

Gambar 6. Sequence diagram login kaprodi.

Gambar 6 menunjukkan diagram sequence proses login KaProdi. Setiap login berhasil, pengguna dihadapkan dengan menu prodi.

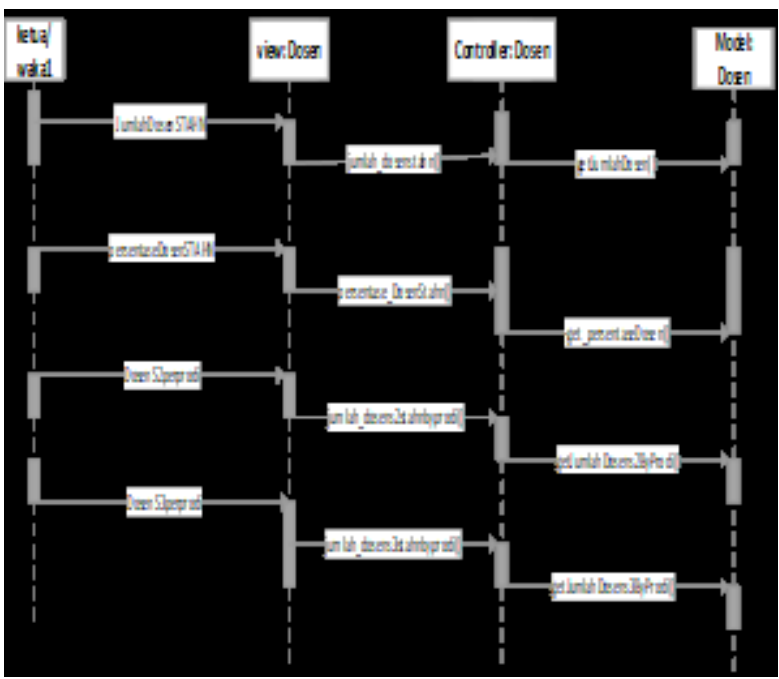

Gambar 7. Sequence diagram dosen. 
Gambar 7 menunjukkan diagram sequence dari fasilitas informasi dosen. Dalam fasilitas ini, ketua atau Wakil ketua 1 dapat melihat informasi tentang dosen di STAHN Gde Pudja Mataram.

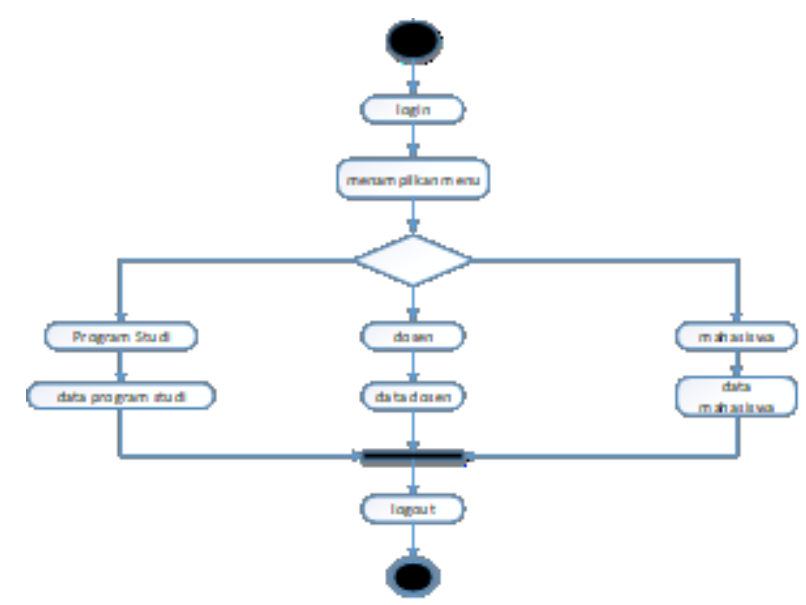

Gambar 8. Activity diagram level 1.

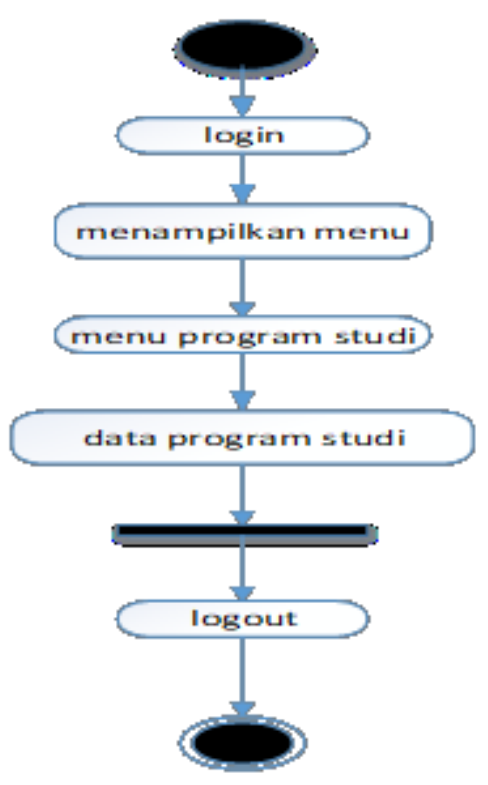

Gambar 9. Activity diagram level 2.

Gambar 8 dan 9 menunjukkan diagram aktivitas pengguna dalam sistem. Diagram aktivitas dibagi menjadi diagram level 1 dan diagram level 2.

\section{IMPLEMENTASI, HASIL DAN PEMBAHASAN}

\section{A. Implementasi Interface}

Halaman awal dari SIE STAHN Gde Pudja Mataram setelah login adalah antar muka yang menyajikan dua menu, seperti yang terlihat dalam Gambar 10, yaitu load data warehouse dan upload data eksternal. Load data warehouse digunakan untuk mulai melakukan proses ETL sampai semua data siap digunakan oleh sistem. Sedangkan upload data eksternal digunakan sebagai sumber data eksternal melengkapi data dari akademik yang telah ada di basis data.

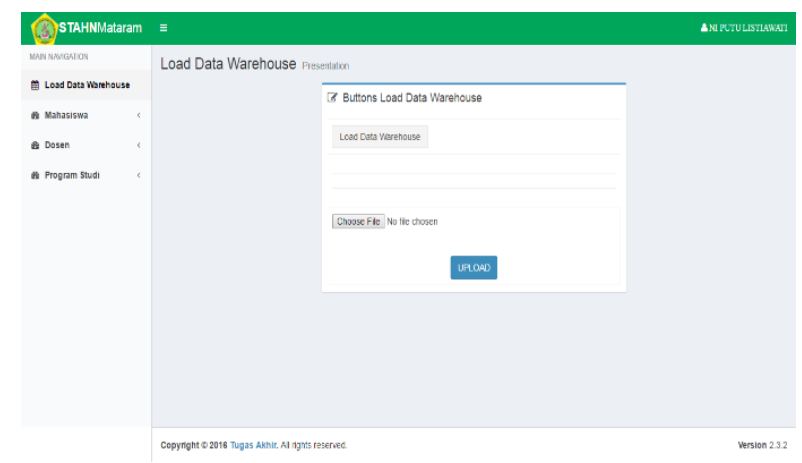

Gambar 10. Halaman awal SIE STAHN.

Salah satu informasi yang dapat disajikan oleh sistem ini adalah grafik perkembangan jumlah mahasiswa baru yang diterima di STAHN Gde Pudja Mataram selama 5 tahun terakhir. Gambar grafik perkembangan mahasiswa STAHN Gde Pudja Mataram selama 5 tahun terakhir ditunjukkan oleh Gambar 11.

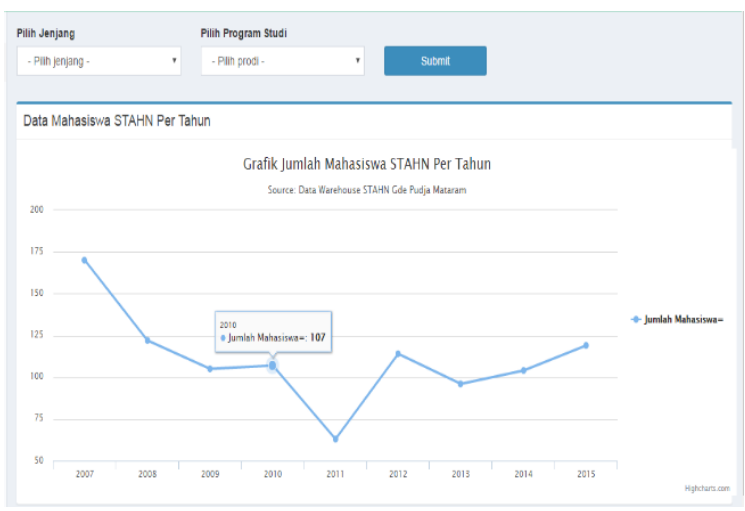

Gambar 11. Line chart data mahasiswa STAHN per tahun.

Fitur lain yang disediakan sistem adalah komposisi jumlah mahasiswa berdasarkan jenis kelaminnya. Data dapat ditampilkan secara menyeluruh untuk semua program studi maupun secara granular terhadap program studi tertentu dan jenjang pendidikan tertentu. Grafik perbandingan jumlah mahasiswa laki-laki dan perempuan disediakan oleh Gambar 12. 


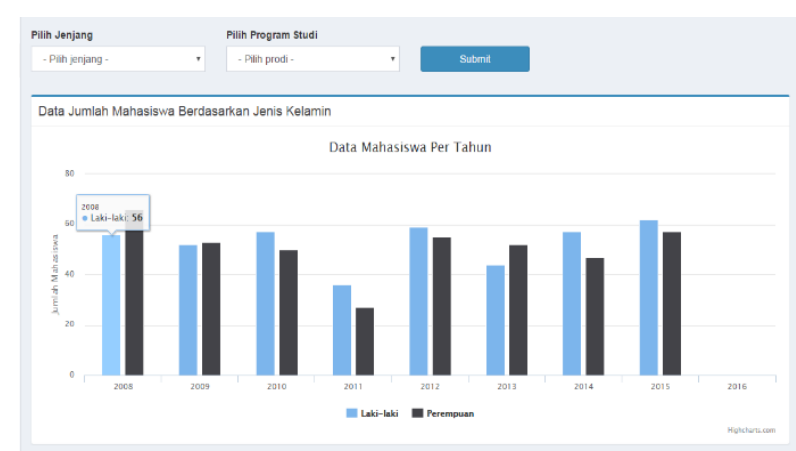

Gambar 12. Chart perbandingan jumlah mahasiswa.

Fitur lainnya yang dapat dimanfaatkan adalah informasi tentang status mahasiswa. Data mahasiswa aktif, cuti, lulus dan drop out dapat dilihat seperti yang disajikan dalam Gambar 13.

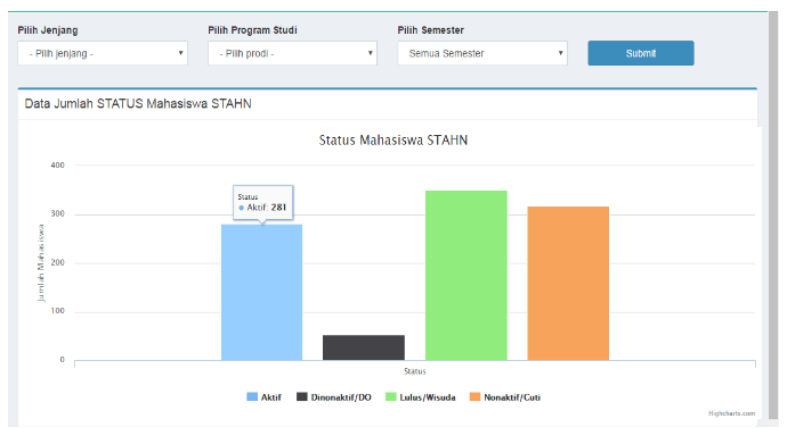

Gambar 13. Data status mahasiswa.

Perbandingan jumlah dosen berdasarkan jenjang pendidikannya juga dapat ditampilkan, seperti terlihat pada Gambar 14.

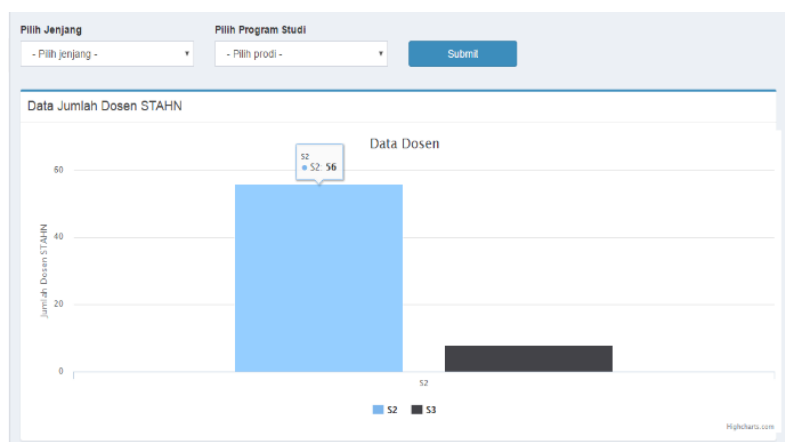

Gambar 14. Jumlah dosen STAHN Gde Pudja Mataram.

Sistem juga dapat menampilkan persentase dosen dengan jenjang pendidikan S2 dan S3. Tampilan persentase jumlah dosen berdasarkan pendidikan tersebut dapat dilihat pada Gambar 15.

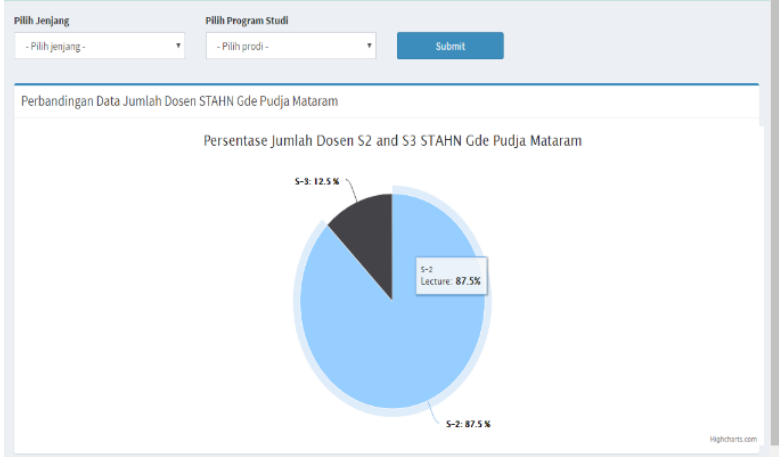

Gambar 15. Persentase jumlah dosen S2 dan S3 STAHN.

Berdasarkan pengujian black box yang telah dilakukan terhadap seluruh fungsi di dalam sistem, semua fungsi tersebut telah berjalan dengan baik dan sesuai dengan yang diharapkan. Dengan hasil tersebut, dapat disimpulkan bahwa dari segi fungsionalitasnya, sistem informasi eksekutif ini sudah berjalan dengan baik.

\section{KESIMPULAN}

Ada beberapa kesimpulan yang dapat diambil berdasarkan hasil pembahasan pada sistem informasi yang dibuat di antaranya :

1. Penggunaan data warehouse mampu membuat query lebih efisien tanpa harus melakukan banyak join ke tabel yang lain.

2. Sistem informasi eksekutif yang dibangun mampu memberikan resume informasi kepada eksekutif STAHN Gde Pudja Mataram untuk mengambil kebijakan - kebijakan penting dimasa yang akan datang. Sistem informasi eksekutif ini mampu memberikan informasi secara lebih detail yaitu dari data yang sifatnya menyeluruh sampai data yang lebih khusus.

3. Sistem informasi eksekutif yang dibuat dapat memberikan informasi kepada eksekutif mengenai data mahasiswa, data dosen dan data masing-masing program studi STAHN Gde Pudja Mataram dalam bentuk grafik dan tabel.

4. Sistem informasi eksekutif mampu memberikan informasi tentang persentase dosen dan persentase jumlah mahasiswa laki-laki dan perempuan STAHN Gde Pudja Mataram.

5. Sistem mampu memberikan informasi prestasi mahasiswa atau IPK seluruh mahasiswa aktif STAHN Gde Pudja Mataram dengan mudah.

6. Sistem memberikan kemudahan kepada eksekutif dalam melakukan load data dari database SIA STAHN Gde Pudja Mataram ke dalam data warehouse.

\section{SARAN}

Dikarenakan masih banyak kekurangan dari penulis dalam membangun sistem ini, terdapat beberapa saran 
untuk dapat membuat sistem ini menjadi lebih baik pada waktu yang akan datang, di antaranya:

1. Menambahkan lebih banyak user stories atau kebutuhan-kebutuhan data untuk memenuhi kelengkapan informasi ke level eksekutif.

2. Menambahkan data dari sumber-sumber data yang lain seperti data mahasiswa sekolah menengah atas dari website MENDIKBUD dan melalui media online yang lain yang nantinya dipilah dan di-load ke data warehouse untuk kebutuhan data yang lain.

3. Saat ini data di-load masih dilakukan dengan proses manual yaitu belum pada tahap terkoneksi/terhubung secara otomatis dengan SIA STAHN Gde Pudja Mataram sehingga untuk ke depannya diharapkan database SIA STAHN Gde Pudja Mataram terhubung dengan data warehouse secara otomatis melalui jaringan secara online sehingga mempermudah loading data.

4. Data yang di-upload dari luar database sistem informasi akademik masih bersifat data percobaan untuk memenuhi konsep struktur data warehouse sehingga ke depan diharapkan bagi yang berkeinginan melanjutkan tugas akhir ini supaya mencari data valid terkait jumlah mahasiswa yang beragama Hindu pada sekolah menengah atas yang ada di provinsi NTB supaya eksekutif kampus STAHN Gde Pudja Mataram bisa mengambil langkah-langkah promosi ke depannya agar peminat siswa Sekolah Menengah
Atas yang beragama Hindu berkeinginan mendaftar di STAHN Gde Pudja Mataram.

\section{DAFTAR PUSTAKA}

[1] V. Oktariana, Waslaludin, dan Y. Wibisono, "Executive Information System Di Organisasi Sekolah Menengah Atas," PTIK, vol. 3, no. 1, 2010.

[2] T. Kaniclides and C. Kmble, Executive Information System. London, 1994.

[3] T. Arifianto dan M. Sofi, "Rancang Bangun Sistem Informasi Eksekutif Berbasis Web di STMIK Yadika Bangil," SPIRIT, vol. 6, no. 1, pp. 25-33, 2014.

[4] A. Dawan, "Sistem Informasi Eksekutif Berbasis Web pada Fakultas Teknik Universitas Diponegoro," Makal. Semin. TA Univ. Diponogoro.

[5] Y. Priyandari, I. Iftadi, dan S. Sundari, "Rancangan Informasi Eksekutif untuk Bidang Akademik dan Kemahasiswaan di Universitas Sebelas Maret," Performa, vol. 10, no. 2, pp. 131-140, 2011.

[6] E. Martha dan D. Agushinta, "Analisis dan Perancangan Sistem Informasi Eksekutif Studi Kasus Pada Sekretariat Kabinet," in Sentika, 2012.

[7] T. Yulianto, I. Bagus, K. Widiartha, I. Wayan, dan A. Arimbawa, "Rancang Bangun Sistem Informasi Geografis Fasilitas Umum Kota Mataram Berbasis Web (Design and Implementation of Web based Geographical Information System of Public Facility in Mataram City)."

[8] I. Hadi, I. B. K. Widiartha, dan I. W. A. Arimbawa, "Desain dan Implementasi Service Oriented Architecture Pada Sistem Informasi Geografis Pemerintah Kabupaten Lombok Barat," J. Comput. Sci. Informatics Eng., vol. 1, no. 1, p. 33, Jan. 2018. 